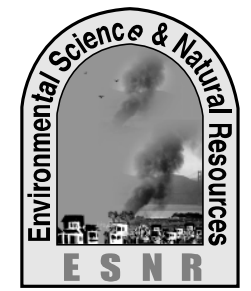

\title{
Waste Generation and Management Practices in BSCIC Mymensingh
}

\author{
M. S. Rahman, S. Datta and S. Islam \\ Department of Farm Structure and Environmental Engineering \\ Bangladesh Agricultural University, Mymensingh-2202, Bangladesh
}

\begin{abstract}
The present study was undertaken to quantify the waste generation in BSCIC, Mymensingh and to identify the waste disposal and management system for forecasting the environmental impacts of these wastes. Data were collected through a pre-tested questionnaire from 50 industries and a recycling plant divided in categories based on their daily production capacity. The study shows that total waste generation was $9758 \mathrm{~kg} /$ day of which $34.53 \%$ wastes were from puffed rice mills, $27.42 \%$ from mustard oil industries, $8.89 \%$ from fertilizer and pesticide industries, $6.8 \%$ from flour mills, $6.49 \%$ from bakery food industries, $2.83 \%$ from coconut oil mills, and $13.04 \%$ from all other industries. Small, medium and large category industries produced $1223 \mathrm{~kg} /$ day, $3115 \mathrm{~kg} /$ day and $5420 \mathrm{~kg} /$ day of wastes, respectively. Most of the generated wastes were solid and liquid. Some industries recycled the wastes as a part of manufacturing process. It was found that $44.19 \%$ industries sell wastes to poultry, fisheries and livestock personnel for making profit, $39.53 \%$ use municipal waste as management system, $13.95 \%$ recycle their wastes onsite or sending the wastes to waste recycling plant, and $2.32 \%$ industries sell the wastes for biomass burner fuel. Roadside solid wastes are picked up by municipal waste management system and liquid effluents pass its way through the municipal drains to the Brahmaputra River. Leftover wastes are not significant enough to cause environmental degradation. No serious complains about health hazard or pollution in environment was found from the surrounding community.
\end{abstract}

Key words: BSCIC, Management, Mymensingh, Waste

\section{Introduction}

Bangladesh is becoming an industry-intensive country day by day. Industrial development is playing a dynamic role in socio-economic aspect of the country. On the other hand this vigorous industrial development is affecting the environment around us. Wastes from industries are constantly degrading the environmental quality and earth's ecosystem directly and indirectly. Discharge of wastes without proper treatment and without following environmental laws and regulation is causing severe degradation of environmental components resulting in both global warming and greenhouse effect.

In general waste is considered as a matter if it is in wrong place. However, waste may be defined as the damaged, defective or surplus material produced by a manufacturing process, discarded materials from agriculture and forestry, edible materials from the kitchen, refuse available from the place of human and animal habitation which are allowed to escape without utilized or are under-utilized on the site (Varshney, 1987). According to EPA (1990) waste is defined as any substance which constitutes as scrap material or other unwanted surplus substance arising from the application of any process and according to WHO (1971) solid waste is defined as useless, unwanted or discarded materials and are not free flowing. Wastes can also be defined as useless, unwanted, and discarded materials coming from production and consumption (Ahmed and Rahman, 2000).

The industries in our country usually do not follow the recommended settlement pattern in the most urban areas and also do not follow the systematic land use plan and some of these are not established in a planned manner. Instead, they are scattered all over the urban settlement both in commercial and residential areas. So degradation due to this indiscriminate disposal of industrial wastes has become a growing concern in Bangladesh. The management of wastes in industries requires systematic approach, handling, storage and disposal to mitigate the risk to health and environment and enhance positive measures to a degree that will promote sustainable environmental quality.

On the light of waste generation in Bangladesh, BSCIC (Bangladesh Small \& Cottage Industries Corporation) is providing infrastructural facilities, having established 79 industrial estates throughout the country that are generating a large amount of wastes or refuse for everyday operation and maintenance. BSCIC industries are manufacturing and assembling a variety of products that releases different types of wastes often without any treatment at all. These processes are degrading the environmental components because of improper handling and lack of transportation facilities, recycling facilities and processing plants. The waste generation quantity differs from industry to industry. Therefore, an attempt was made to analyze the present status of industrial waste generation and their management systems in all industries of BSCIC, Mymensingh.

\section{Methodology}

A detailed survey was undertaken to fulfill the research objectives in all listed industries in BSCIC, Mymensingh. The study was conducted from January to October 2013. In January to June an initial study was conducted as reconnaissance to collect baseline information about BSCIC industries 
of Mymensingh and their types. Generally these data were collected from BSCIC administration and a few through personal interviews. Afterwards, detailed study was directed between July and
October 2013. A total of 50 industries as shown in Table 1 of different categories based on products type with a recycling plant in BSCIC, Mymensingh were investigated.

Table 1 Categorized list of industries in BSCIC, Mymensingh

\begin{tabular}{|c|c|c|}
\hline Serial No. & Category of the Industry & Number \\
\hline 1. & Aluminum utensils industry & 1 \\
\hline 2. & Ayurvedic medicine industry & 1 \\
\hline 3. & Bakery food industry & 4 \\
\hline 4. & Bicycle parts manufacturing industry & 2 \\
\hline 5. & Chanachur and noodles industry & 1 \\
\hline 6. & Coconut oil industry & 2 \\
\hline 7. & Electric cables manufacturing industry & 3 \\
\hline 8. & Fertilizer and pesticide industry & 1 \\
\hline 9. & Flour mill & 2 \\
\hline 10. & Puffed rice industry & 5 \\
\hline 11. & Marble industry & 1 \\
\hline 12. & Masala industry & 1 \\
\hline 13. & Mosquito coil industry & 3 \\
\hline 14. & Mustard oil industry & 16 \\
\hline 15. & Nail production industry & 1 \\
\hline 16. & Packaging industry & 1 \\
\hline 17. & Pesticide industry & 1 \\
\hline 18. & Plastic production industry & 1 \\
\hline 19. & Mat production industry & 1 \\
\hline 20. & Printing industry & 1 \\
\hline 21. & Small parts manufacturing plant & 1 \\
\hline 22. & Vermicelli manufacturing mill & 1 \\
\hline 23. & Recycling industry & 1 \\
\hline
\end{tabular}

In order to collect relevant information, a detailed interview schedule or questionnaire was prepared to accumulate the various important data relating type, size, production capacity, waste generation, disposal, management, chemicals sued in the industry, number of employees etc. The questionnaire was prepared carefully keeping the objectives of the study in mind. The schedule was prepared in English for effective evaluation of the collected data but the communication was made in Bengali for better understanding. Before finalizing the schedule it was pre-tested for judging the suitability to respondents, modification and alternations accordingly.

The method used for collecting data was personal interview to ensure highest level of data retention rate. Firstly purpose of the study was made clear to the respondents and they were asked to help courteously and cooperate in the data collection. The administrative staff of BSCIC, Mymensingh also extended their help in the process which actually made the information provided by respondents more concrete. The respondents provided information from their memory and daily work experience. Some industries were unable to provide reasonably accurate data because of lack of the data keeping process. Respondents from these industries provided data on approximate basis. In order to minimize response error, questions were asked in simple Bengali. After every interview the questionnaire was checked for proper recording. The data obtained through interview schedule from all respondents of individual industry were compiled, tabulated and analyzed according to the objective of the study.

\section{Results and Discussion}

There were 50 industries and one recycling plant in BSCIC, Mymensingh. Industries have been divided into three categories for easy representation of data. The classification was based on production quantity i.e. small category (production up to $500 \mathrm{~kg} /$ day), medium category (production between 501 and $1000 \mathrm{~kg} /$ day) and large category (production greater than $1000 \mathrm{~kg} /$ day).

\section{Wastes generation in small category industries}

It is only imperative that small category industries will produce low amount of wastes as its production is low. But this is not the case in all types industries as size is also a matter. There were 13 operational industries in this category. Solid and liquid wastes were of main concern in these industries. Aluminum dust was accumulated in aluminum made utensils industry. Also liquid wastes were generated in pharmaceutical industries. In bakery industries egg shells were main wastes. There are two coconut oil and four mustard oil industries in this category. To present data in an efficient way the average values of data of these industries were taken. 


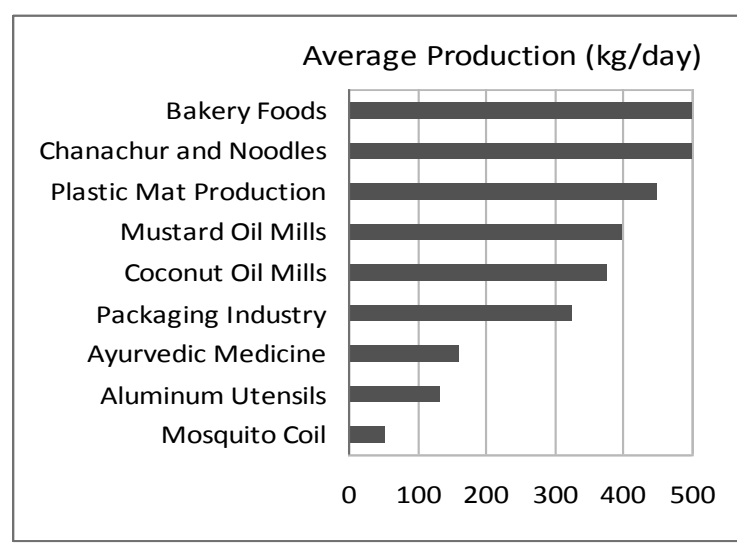

Fig .1. Average production of small category industries

Figure 1 demonstrates production capacity for different types of small category industries. Lowest production was $55 \mathrm{~kg} /$ day for coil industries and highest was $500 \mathrm{~kg} /$ day for chanachur, noodles and bakery foods industries. Plastic mats industry produced 150 mats per day or $450 \mathrm{~kg}$ /day that created only solid wastes which were recycled. Figure 2 illustrates average waste generated from different small category industries. Lowest amount of waste generation resulted from coil industries $(2.5 \mathrm{~kg} /$ day $)$ because of low quantity of production and coil industries often produces wastes. Highest amount of waste accumulation resulted from bakery foods industries which contained mainly egg shells. Aluminum made utensils industries also had low waste generation $(5.5 \mathrm{~kg} /$ day $)$. Packaging and mustard oil mills had approximately the same type waste accumulation as in coconut oil mills. Lowest waste generated according to production was observed for mosquito coil industries at about $4.3 \%$

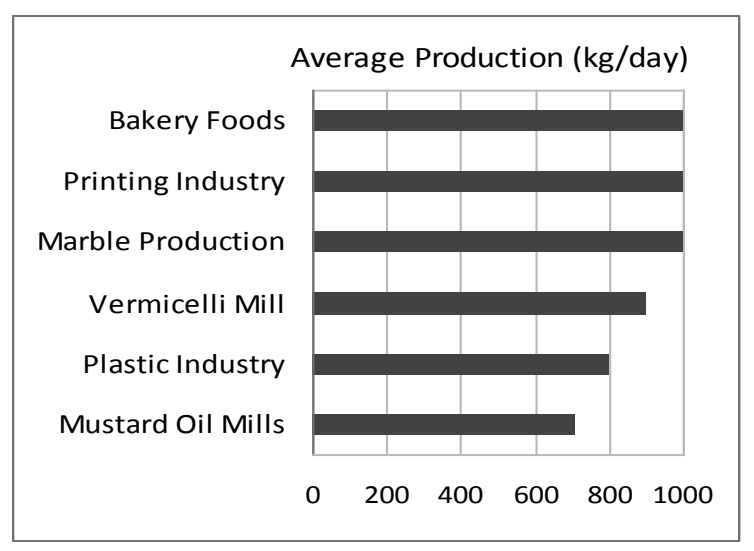

Fig .3. Average production of medium category industries

Figure 3 illustrates the production capacity of different medium catagory of industries. Marble, printing and bakery industries had the same amount of production of $1000 \mathrm{~kg} /$ day. Lowest production was mustard oil of $705 \mathrm{~kg} /$ day. Plastic industry used high density polypropelene, plastic powder as raw materials in manufacturing process. Figure 4 shows that, the waste generation in medium category industries varied from $0 \mathrm{~kg} /$ day to $300 \mathrm{~kg} / \mathrm{day}$.

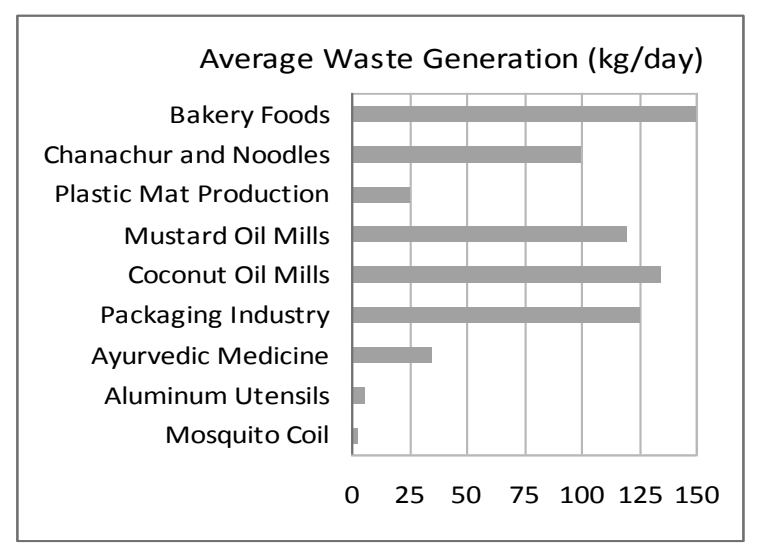

Fig. 2. Waste generation of small category industries

(2.5 $\mathrm{kg}$ waste for $55 \mathrm{~kg}$ production). Highest waste generated from bakery foods industries of about $23.07 \%$ (150 kg wastes for $500 \mathrm{~kg}$ production). Total waste generation for this category was found $1223 \mathrm{~kg} /$ day.

\section{Wastes generation in medium category industries}

There were about 15 industries in this category and the wastes generated were both solid and liquid types. From printing mills, paper debris were the major types of wastes. Plastic industry produced low amount of solid and liquid effluents. Marble production industry did not produce any waste at all. Most of the wastes were recycled as raw materials in a part of manufacturing process. Bakery food industries had large production quantity inspite of having small number of emplyees. There were 10 mustard industries in operation.

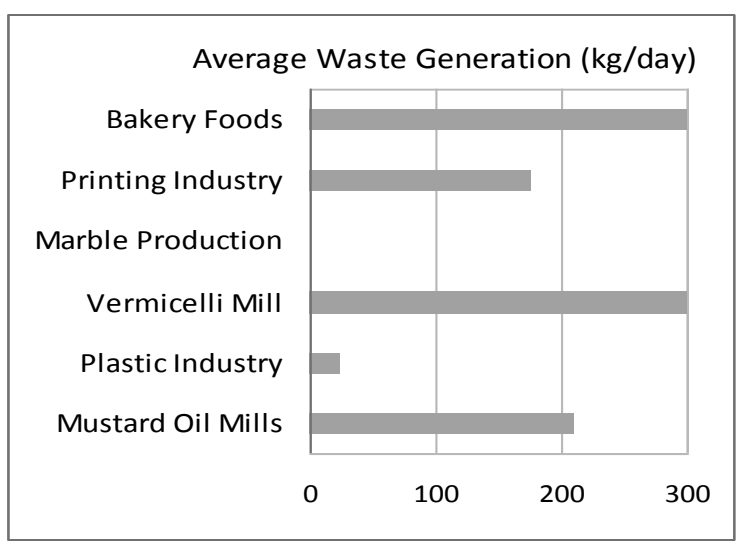

Fig. 4. Waste generation of medium category industries

Marble industry had no waste accumulation, while printing industry produced $175 \mathrm{~kg}$ of paper debris per day. Plastic industry produced very little amount of solid and liquid wastes of about $24 \mathrm{~kg} /$ day as most of them were recycled. Ten mustard oil mills had average waste generation of $211 \mathrm{~kg} /$ day. Lowest amount of waste generated according to production was found from plastic industry at about $2.91 \%$ (24 $\mathrm{kg}$ waste for $800 \mathrm{~kg}$ production) and maximum 
amount of waste generated from vermicelli mills at about $25 \%$ (300 kg wastes for $900 \mathrm{~kg}$ production). Total waste generation for this category was recorded $3115 \mathrm{~kg} /$ day.

\section{Waste generation in large category industries}

There were 11 large category industries. Having the large amount of production, these industries also

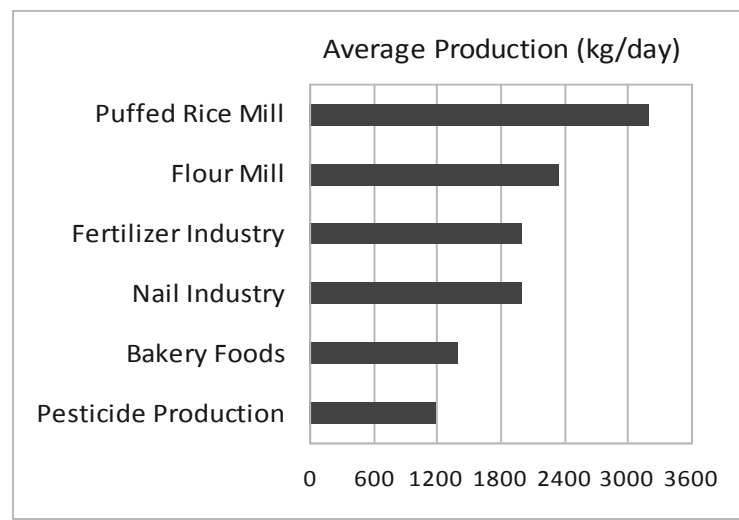

Fig .5. Average production of large category industries

Figure 5 shows the average production capacity for different large catagory industries. It was observed that highest average production took place at puffed rice mills (3200 kg/day) and lowest from pesticide manufacturing industry $(1200 \mathrm{~kg} /$ day $)$. Flour mills also had relatively high production of $2350 \mathrm{~kg} / \mathrm{day}$. Nail and fertilizer industry had the same amount of production of $2000 \mathrm{~kg} /$ day. Figure 6 illustrates the waste generation of different large catagory industries. As obvious, puffed rice produced more wastes on average of $660 \mathrm{~kg} / \mathrm{day}$ and lowest from pesticide production industry $(250 \mathrm{~kg} /$ day $)$. Lowest waste generation according to production capacity was $11.65 \%$ in flour mills and highest was $23.07 \%$ from fertlizer and pesticide industry. Total waste generation in this category was found $5420 \mathrm{~kg} / \mathrm{day}$.

\section{Category-wise otal waste generation}

There were about 23 categories of indistries in terms of products type. The industries that are not currently in operation are bicycle parts, electric cables, small parts manufacturing, one biscuit factory, two mosquito coil manufacturing mills, and one mustard oil mill. Figure 7 shows the major category industries with their production vs waste generation per day. It was observed that five puffed rice mill had highest amount of waste accumulation per day of $3300 \mathrm{~kg}$ with the highest production of $16000 \mathrm{~kg} /$ day. The waste accumulated by this mill was environment friendly and cost effective. On the other hand 15 mustard oil production mills produced $2620 \mathrm{~kg} /$ day of wastes with the second highest production of $8650 \mathrm{~kg} /$ day. It generally produced little amount of solid wastes and reasonable amount of liquid wastes. The lowest quantity of waste produced huge quantity of wastes. Puffed rice mill produces the largest part of wastes in this category, these were particulate mattters and solid dusts. There were also nail industry present in this category which produces splinters and dust. Flour mills produced a little amount of solid and liquid wastes. There were 5 puffed rice mills and 2 flour mills in this category.

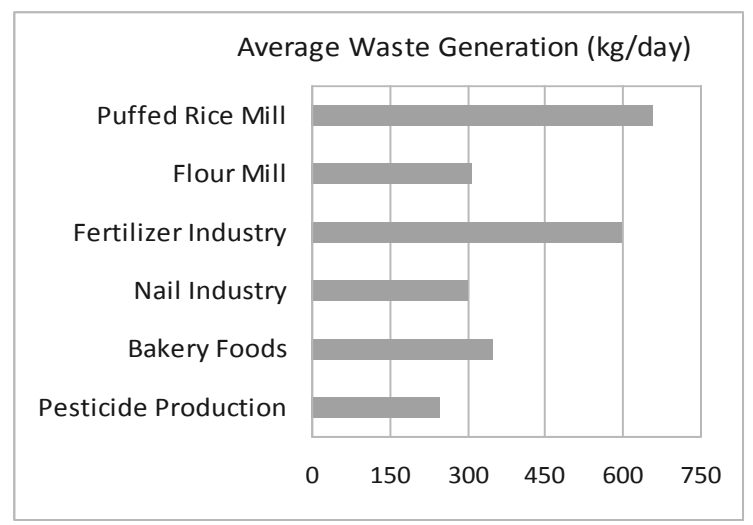

Fig. 6. Waste generation of large category industries

generation was $270 \mathrm{~kg} /$ day from coconut oil mills and production was reasonably lower $(750 \mathrm{~kg} / \mathrm{day})$. So there was a substantial relationship between production and waste accumulation. The minor category industries involve aluminum utensils, ayurvedic medicine, marble production, nail productiom, packaging, plastic and printing industres. These industries accumulated $794 \mathrm{~kg}$ of waste with $5918 \mathrm{~kg}$ of production per day. The total waste was recorded $9758 \mathrm{~kg} / \mathrm{day}$ in the area.

\section{Waste management system in BSCIC, Mymensingh}

Due to unhazardous nature high level of waste management was not necessary for most of the wastes in BSCIC area. A large number of the industries in BSCIC, Mymensingh mostly depended on municipal waste management system. The wastes were collected by municipal labor twice a day, in morning and evening. Most of the wastes were collected from container bins, roadside and dustbins. Vans and push carts are used for onsite storage of wastes. Three vehicles are used for collection and transport the waste from BSCIC to final dumping site. The drains in the BSCIC area were not properly maintained. This drains passed the liquid wastes through the municipal drains and thus finally discharged into the river.

A group of industries like puffed rice, mustard oil industries sold their wastes to fisheries, poultry and livestock personnel as fish and poultry feed and sometimes also for cattle feed. Wastes from nail production industry were sold to scraping yards. Some industries sold their generated wastes to 
Chittagong recycling plant for proper disposal. Aluminum industries recycled their waste materials into industrial grade alum. Pharmaceutical wastes were recycled to fertilizer. All wastes from mosquito coil industries were readily recycled as a part of manufacturing process. In BSCIC, Mymensingh there is a recycling plant that converts

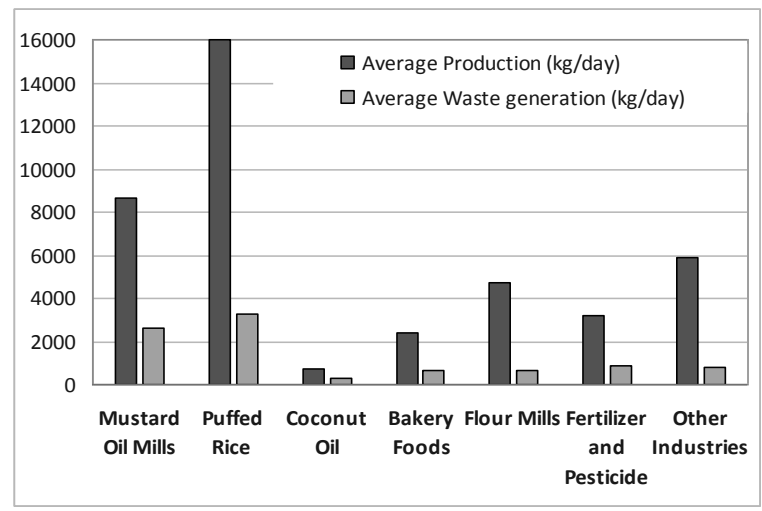

Fig. 7. Category-wise production Vs waste generation

\section{Problems created by the wastes in BSCIC, Mymensingh}

Wastes generated from BSCIC, Mymensingh caused a very little affect on the surrounding environment. Gaseous emissions were not significant enough to cause pollution on large scale. Since most wastes were reused and some were recycled, very few amount of wastes were left in the environment which were not enough to cause environmental degradation. The liquid wastes released from the industries that discharged into the rivers caused little impact on aquacultural life. The sound from nail production industries didn't make its way to sourrounding residential area to cause serious pollution, but employees in the industry facade substantial hearing problems.

\section{Conclusion}

Total waste generation in BSCIC, Mymensingh was found $9758 \mathrm{~kg} /$ day in 50 industries containing various types of wastes. Highest amount of wastes generated from puffed rice industry and lowest amount from mosquito coil industry. As most of the wastes were reused, recycled or disposed, there were very little amount of wastes left in the area and these wastes in the surroundings caused a little impact on the environment. Present waste management in BSCIC, Mymensingh is neither adequate nor satisfactory. At present the industrial representative depends $44.19 \%$ on selling the wastes for profit, $39.53 \%$ on municipal waste management system, $13.95 \%$ on recycling and reusing, and $2.32 \%$ on burner fuel for biomass plants.

Dustbins with adequate capacity should be established at proper location and should be regular monitoring and need periodical maintenance of the dustbin, vehicles and other elements of waste waste material to PVC pipe. Figure 7 illustrates that $44.19 \%$ of wastes in the industrial area was sold to fisheries, poultry and livestock personnel and $39.53 \%$ wastes were collected by municipal workers. Although a consideriable amount of wastes $(13.95 \%)$ was recycled to various products and $2.32 \%$ wastes were used as biomass burner fuel.

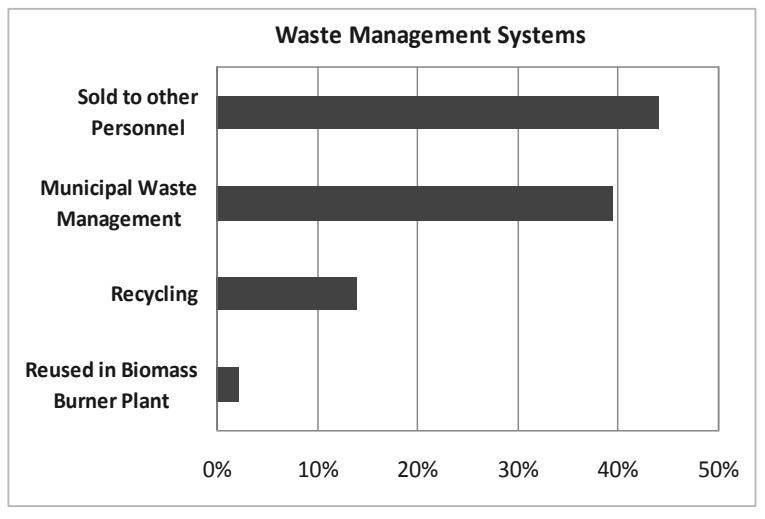

Fig. 8. Waste management practice in BSCIC, Mymenisngh management system. Addition of the efficient vehicles with proper sealing and skilled manpower should be provided. Additional recycling plant should be established in the area to reduce cost of recyclable waste transportation and hazardous spills. Reuse and reduction of wastes should be followed through composting, aqua-cultural feeds, etc. Creation of awareness can be made among people about waste management and its impact on the environment, so that proper handling of waste at core level can be attained. Promotion of training program should be taken to industrial members for better management of waste.

\section{References}

Ahmed, M.A. and Rahman, M.M. 2000. Water supply and sanitation- rural and low income urban communities ITN, Bangladesh. BUET. Dhaka-1000. Bangladesh.

EPA. 1990. Recommended buffer distance for industrial residual air emissions. Environment Protection Authority of Victoria, Publication No. AQ 2186. Melbourne, Australia.

Varshney, A.C. 1987. Rural waste management. Central Inst. Agril. Engg., Bhopal. Associate Publishing Company. Karol Bagh, New Delhi, India.

WHO (World Health Organization) 1971. Safe management wastes from Health Care Activities. Tech. Rep. Ser. No. 484. 